\title{
Persuasão em perspectiva: Elaboration LikelihoohModel e o Modelo de Abordagem Narrativa
}

\author{
Persuasion in perspective: Elaboration Likelihood Model \\ and Narrative Approach Model
}

\author{
Karlan Müller Muniz ${ }^{[a]}$, Eliane Cristine Francisco Maffezzolli ${ }^{[b]}$ \\ [a] Doutorando do Programa de Pós-Graduação em Administração da Pontifícia Universidade Católica do Paraná (PUCPR), Curitiba, \\ PR - Brasil, e-mail: karlanmuniz@gmail.com \\ ${ }^{[b]}$ Doutora em Administração pela Universidade Federal do Paraná (UFPR) e professora adjunta do Programa de Pós-Graduação em \\ Administração da Pontifícia Universidade Católica do Paraná (PUCPR), Curitiba, PR - Brasil, e-mail: eliane.francisco@pucpr.br
}

\begin{abstract}
Resumo
O processo de persuasão e mudança de atitudes é um tema explorado em diversos campos de estudo, com modelos clássicos estabelecidos na área de comportamento do consumidor há mais de 30 anos, como o Elaboration Likelihood Model. Ainda assim, alguns estudos nessa área vêm oferecendo modelos alternativos que rivalizam com ou complementam o conhecimento existente sobre o assunto. No contexto acadêmico brasileiro, especificamente na área de publicidade, os modelos de persuasão são poucos explorados, e não existem trabalhos que enfoquem o modelo de processamento narrativo e seu mecanismo de transportation visando à posterior mudança de atitudes do consumidor. Este artigo procura preencher esta lacuna apresentando revisão teórica sobre os dois modelos e discutindo as diferenças e os espaços para o desenvolvimento acadêmico em torno deste tema, em relação a gaps na teoria existente e especificamente no contexto brasileiro.
\end{abstract}

Palavras-chave: Persuasão. Elaboration Likelihood Model. Narrativa.

\section{Abstract}

The process of persuasion and attitude change is a theme explored in many fields of study, with classic models established in the area of consumer behavior for over 30 years, as the Elaboration Likelihood Model. Nevertheless, some studies 
in this area have offered alternative models that compete with or complement the existing knowledge on the subject. In the academic context of Brazil, specifically in the area of advertising, a few models of persuasion are explored, and there are no studies that addressed the processing model and its mechanism of narrative transportation with the aim to change consumer attitudes. This article seeks to fill this gap by presenting theoretical review of the two models and discuss the differences and spaces for the academic development around this theme in relation to gaps in existing theory and specifically in the Brazilian context.

Keywords: Persuasion. Elaboration Likelihood Model. Narrative.

\section{Introduçáo}

Uma pesquisa do Ibope Inteligência identificou que $87 \%$ dos brasileiros gostam de publicidade e que $67 \%$ consideram que ela tem um papel importante em suas vidas (IBOPE, 2010). No entanto, uma pergunta possível diante dessa constatação é se a publicidade efetivamente cumpre seu papel na comunicação de marcas e produtos. Segundo Armstrong (2010), a publicidade pode ser considerada uma ação que pretende influenciar os outros por meio de mensagens por todos os tipos de mídia.

$\mathrm{Na}$ discussão sobre a função da publicidade, emerge a necessidade de discutir sua eficácia. Um antigo CEO da agência de publicidade mundial Ogilvy \& Mather, Graham Philip, afirmou em artigo da Advertising Age em 2002 que

uma parte grande demais da publicidade atual é irrelevante e um desperdício de dinheiro. Há dez anos observadores tem percebido que as agências de publicidade parecem mais interessadas em vender o seu produto do que o produto de seus clientes. De lá para cá, isso tem ido de mal a pior (PHILLIPS, 2002).

De fato, uma propaganda que não se mostra persuasiva pode ser considerada um investimento inútil, e o estudo dos processos de persuasão e seu impacto no comportamento do consumidor se mostra relevante para o aprofundamento de teorias nas áreas de comunicação e marketing, além de permitir o aperfeiçoamento da técnica da publicidade.

O presente trabalho enfoca o processo de persuasão, repassando pesquisas na área do comportamento do consumidor, da psicologia e da comunicação. Investigações contemporâneas revelaram novos processos de persuasão, como a narrativa e seu mecanismo de transportation, como novo paradigma apoiando o avanço em estudos no campo da persuasão (GREEN; BROCK, 2000) e na formação de imagens mentais do consumidor (PETROVA; CIALDINI, 2008).

A intenção, então, é revisar e contrastar dois modelos de persuasão e seus impactos na eficácia da propaganda. Este artigo inicia com a revisão do objetivo da persuasão em marketing - a mudança de atitudes e crenças -, aborda o processo de persuasão mais explorado nos últimos 30 anos na área de comportamento do consumidor, o Elaboration Likelihood Model (ELM), e explora um paradigma alternativo que tem ganhado espaço nos últimos quinze anos na área de comportamento do consumidor, o modelo ou paradigma narrativo. Uma análise compara os processos, procurando explorar limitações e vantagens e explorar variáveis que podem impactar na eficácia de ambos.

\section{A persuasão na comunicação: mudando crenças e atitudes}

A persuasão, relacionada com a formação ou mudança de atitudes, e concretizada pelo desenvolvimento de campanhas, intervenções e estratégias persuasivas, tem papel preponderante porque pesquisadores e psicólogos sociais acreditam que a mudança de atitude implica mudança de comportamento (HAUGTVEDT; KASMER, 2008). Vale ressaltar que, além de divulgar, a propaganda funciona como um método em potencial para a transferência de significado, combinando o produto ou marca anunciada à representação de um mundo culturalmente constituído, tudo dentro do enquadramento de um anúncio em particular (McCRACKEN, 1986). Isso 
também corrobora o efeito de persuasão, a intenção da intervenção na visão de mundo.

Estudiosos afirmam que a efetividade da propaganda está relacionada ao seu poder de convencer o público a escolher seu produto (VAKRATSAS; AMBLER, 1999). E, dentro do contexto da propaganda persuasiva, segundo Shimp (2009), não existe uma única maneira de influenciar as pessoas a formar atitudes favoráveis em relação às marcas, ou agir conforme almejado pelos comunicadores de marketing. Segundo Belch e Belch (2008), existem várias possibilidades de execução publicitária - que é o modo pelo qual o apelo publicitário é apresentado - incluindo a mensagem factual, a demonstração, a comparação, o testemunho, a dramatização, entre outras.

Em seu livro clássico sobre persuasão e mudança de atitude, Petty e Cacioppo (1981) enumeram sete abordagens que procuram explicar os processos básicos inerentes à mudança de atitude, explorando princípios do condicionamento e modelagem (administração de recompensas e punições), a abordagem de teoria da aprendizagem de Hovland e dos pesquisadores de Yale (com foco na atenção, compreensão e retenção da mensagem), a abordagem da percepção e julgamento (na qual o indivíduo percebe a mensagem de acordo com o contexto e com experiências passadas), a abordagem das motivações humanas (que por si inclui teorias como a da congruência, da busca por equilíbrio/ consistência pelo ser humano e da dissonância cognitiva), teorias que exploram as inferências que o receptor faz acerca do comportamento do comunicador e de si mesmo, de abordagens combinatórias, envolvendo probabilidades e modelos matemáticos, e de abordagens de autopersuasão (informações geradas pelas próprias pessoas em resposta a uma mensagem persuasiva). Desses estudos, a rota principal encontrada é o Elaboration Likelihood Model.

\section{O Elaboration Likelihood Model (ELM)}

O Elaboration Likelihood Model (PETTY; CACIOPPO;SCHUMANN, 1983) é considerado um modelo dominante na teoria da persuasão e mudança de atitude (segundo ZHENG, 2010; PERLOFF, 2010; GRIFFIN, 2012). Como afirmam Haugtvedt e Kasmer (2008), o ELM foi inicialmente proposto como um meio de entender por que os resultados de alguns estudos sobre mudanças de atitude podiam ser caracterizados como relativamente fortes (persistentes), enquanto os resultados de outros estudos de mudança de atitudes podiam ser caracterizados como fracos (não persistentes).

Petty e Cacioppo (1981) argumentam que a literatura existente sobre persuasão, mesmo com diversas divergências conceituais e de efeitos, acabam enfatizando duas rotas distintas para a mudança de atitude. O ELM apresenta dois possíveis processos de persuasão: a rota central, caracterizada pela intensa elaboração cognitiva dos argumentos da mensagem, para altos níveis de envolvimento, e uma rota periférica, quando existe pouca motivação ou habilidade para o processamento de informações, e o receptor usa outras pistas como a atratividade ou atmosfera do anúncio para determinar a adequação e atitude resultantes para com o comercial e com a marca (PETTY et al., 1983). A rota central é enfatizada pelas teorias de atenção, compreensão e retenção da mensagem, pela teoria sobre as informações geradas pelo receptor diante da mensagem persuasiva e pela teoria de que as pessoas combinam informações para avaliá-las (PETTY; CACIOPPO, 1981). Uma abordagem bem racional e "elaborada", portanto.

A rota periférica apresenta uma figura bastante distinta, e aqui estão presentes pistas relacionadas a fatores como aqueles mencionados na teoria do condicionamento (recompensas e punições), distorções mencionadas pela teoria do julgamento baseado na percepção do emissor e pela teoria sobre as inferências que o receptor faz a cerca do comunicador (PETTY; CACIOPPO, 1981). Nessa rota, o pensamento não é tão elaborado e a mensagem é aceita pela sua atratividade ou por "soar bem" ao receptor. Enquanto na rota central a força dos argumentos é aspecto essencial para mudança de atitude, na rota periférica algumas pistas podem ser a base da mudança de atitude, como a atratividade da fonte, o número de argumentos (e não a natureza destes), a atmosfera e os sentimento gerado pela mensagem etc.

O resultado da mudança de atitude via rota central é caracterizado como implicando estruturas cognitivas mais extensas e integradas, enquanto a mudança de atitude pela rota periférica é caracterizada por ligações menores e mais fracas. E a distinção entre as rotas de processamento é caracterizada pela probabilidade - alta ou baixa - de elaboração da mensagem por parte do receptor. 


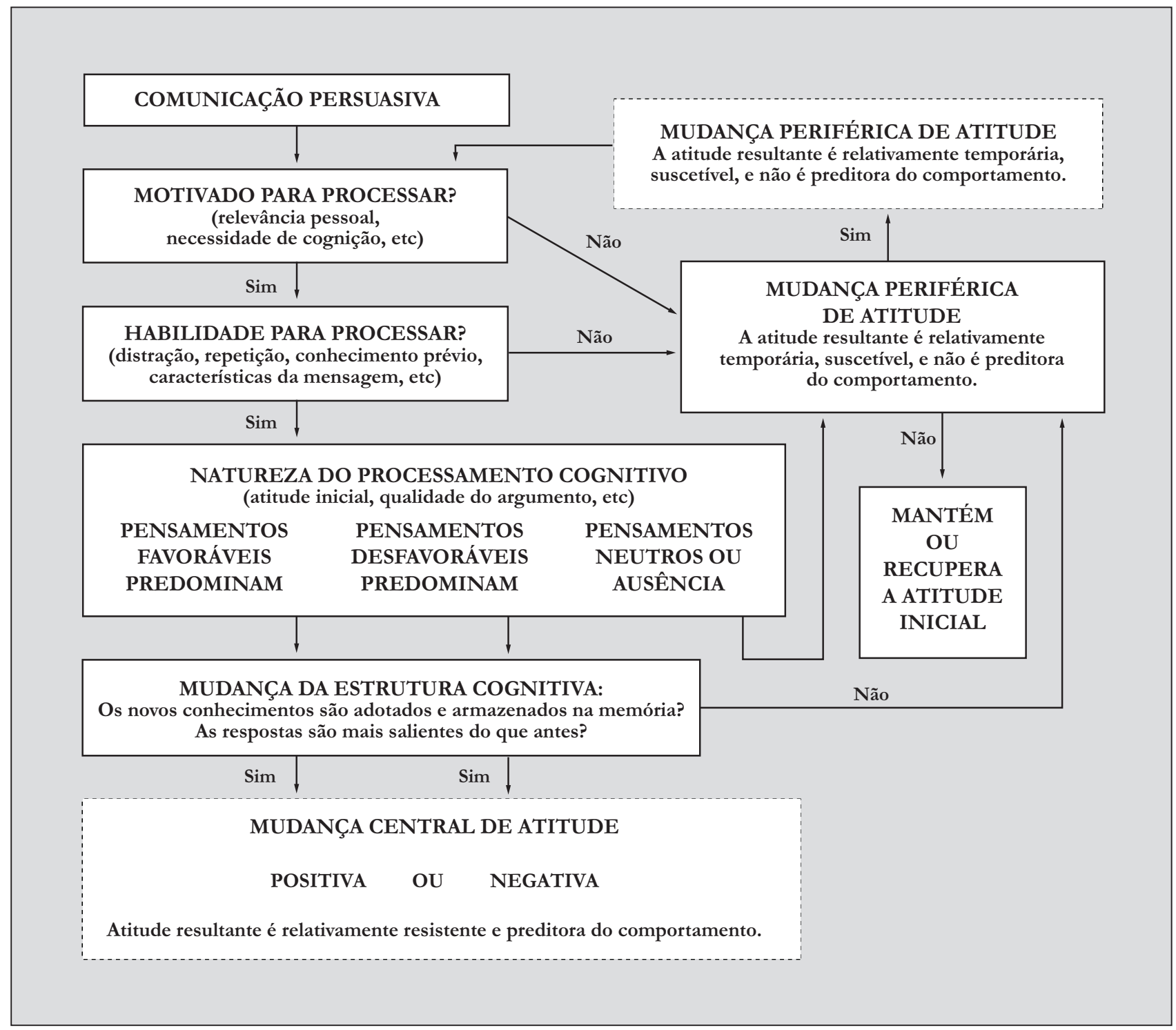

Figura 3 - Rotas central e periféricas para a persuasão, descrevendo os dois pontos finais de ancoragem do Elaboration Likelihood Model

Fonte: Petty e Cacioppo (1981) e Cacioppo e Petty (1989).

É importante mencionar que, apesar das duas rotas distintas, os autores do modelo não endossam uma divisão arbitrária em duas frentes - uma divisão simples em alto e baixo volume de elaboração, ou em alto e baixo envolvimento do consumidor - , mas defendem a ideia de um continuum de elaboração (HAUGTVEDT; KASMER, 2008). A Figura 1 a seguir apresenta o modelo de probabilidade de elaboração (tradução do Elaboration Likelihood Moded), proposto por Petty e Cacciopo (1981) e Cacioppo e Petty (1989) para a mudança de atitude.

De acordo com a teoria e com a Figura 1 apresentada, construtos como o nível de envolvimento, necessidade de cognição e habilidade de elaboração servem como moderadores para levar o consumidor a um processamento via rota central ou periférica. Os autores do ELM traduzem o envolvimento como o grau de relevância pessoal e cujo resultado implica mais conexões pessoais 
com a mensagem da propaganda (PETTY et al., 1983). Buchholz e Smith (1991) traduzem em dois componentes o envolvimento com uma mensagem de propaganda: uma maior atenção ao anúncio e um foco maior no processamento da mensagem da marca. Zaichkowsky (1985) define envolvimento como a relevância percebida de um objeto, baseado nas necessidades, valores e interesses inerentes à pessoa.

A teoria do Elaboration Likelihood Model fornece conselhos práticos e tem liderado a pesquisa na área nos últimos vinte anos, com centenas de artigos publicados só na área de comunicação (GRIFFIN, 2012). No entanto, Griffin (2012), quando revisa a teoria, faz uma crítica, mencionando que o modelo cresceu em complexidade neste período, comportando-se de forma menos preditiva e menos capaz de fornecer conselhos para o comunicador, o que vai contra os preceitos desejados para uma teoria científica. Autores como Boller e Olson (1991) mencionam que, embora muitos anúncios sigam o formato argumentativo, o que explica a importância e o uso do Elaboration Likelihood Model, este modelo tem poder limitado de explicação quando se trata de anúncios usando narrativas.

\section{As narrativas e o comportamento do consumidor}

Muitos estudos que enfocam técnicas de persuasão na psicologia abordam a narrativa como uma alternativa ao raciocínio argumentativo. Existem trabalhos que tratam da diferença entre os dois processos de persuasão na área de teoria da comunicação (FISHER, 2012), na área da psicologia (BRUNER, 1986) e na área de comportamento do consumidor (ESCALAS, 2007), além de referências nas áreas de estudo da literatura, história, direito e economia (LEONG; ANG; HENG, 1994; ZHENG, 2010). $O$ uso de narrativas é discutido até mesmo na construção e publicação de pesquisas na área de psicologia do consumidor (PERACCHIO; ESCALAS, 2008).

A literatura de psicologia mostra que as narrativas servem ao processo de organização cognitiva dos consumidores (POLKINGHORNE,1991). Muitas das informações e experiências sociais que o consumidor adquire em sua vida são transmitidas na forma de narrativas (ADAVAL; WYER, 1998). Escalas e Bettman (2000) descrevem os consumidores como construtores de estórias, sendo que o maior foco das estórias criadas por eles faz sentido para dizer quem eles são e o que eles consomem. Com base em ampla pesquisa na literatura, Woodside, Sood e Miller (2008) argumentam que existem cinco proposições para comprovar a importância das estórias na psicologia do consumidor: primeiro, as pessoas raciocinam de forma narrativa, ao invés de fazer uso de elaborações argumentativas; segundo, as informações são armazenadas e recuperadas da memória na forma de episódios; terceiro, as pessoas buscam clareza nas experiências e nos resultados que vivenciam, organizando-os em forma de estórias; quarto, as pessoas sentem prazer em reviver ou recontar estórias para experienciar - ainda que inconscientemente - mitos arquetípicos; e, por fim, as marcas e os produtos exercem papéis importantes ao capacitar os consumidores a atingirem seus resultados e a viverem papéis que lhe dão prazer e felicidade. Os informantes no estudo de Fournier (1998) também descrevem o papel das marcas e o seu relacionamento com elas na forma de estórias, incluindo-as em suas histórias de vida.

Além de representar uma base estrutural para a memória humana (SCHANK; ABELSON, 1995), na área da educação a abordagem narrativa é vista como um dos meios mais favoráveis para a educação de gerações mais novas e o engajamento de adultos, pois propicia condições ótimas para a projeção do leitor pretendido no protagonista com quem partilha não só a idade, mas também as vivências que lhe são comuns (MAGALHÃES, 2009), funcionando, assim, como eficiente meio de transmissão e pré-vivência. Green (2004) afirma que antes dos recursos audiovisuais de hoje, os professores sentavam junto dos alunos e contavam estórias; recurso esse que gera informações mais fáceis de lembrar. No contexto de consumo, a decisão de compra está baseada nas implicações do produto/marca em uma sequência de eventos como um todo, ao invés do simples julgamento das características (ADAVAL; WYER, 1998). As narrativas servem ao processo de organização cognitiva dos consumidores, em que o significado de eventos e ações individuais da vida de alguém é derivado desses acontecimentos para o todo (POLKINGHORNE, 1991), e as pessoas constroem mentalmente sua biografia em forma de 
narrativa, em um constante processo de interpretação e reinterpretação da experiência (BRUNER, 2004). Além de ver a própria identidade em termos de uma lista de atributos - como altura, beleza, capacidade de realização etc. -, esses atributos são ligados na memória a episódios-chave, que, colocados em ordem, formam uma estória (BELK, 1988; AHUVIA, 2005).

\section{Modelo de abordagem narrativa: transportation}

Perloff (2010) afirma, em seu texto sobre persuasão, que a literatura acadêmica em persuasão negligenciou o impacto das narrativas públicas nas atitudes, enfatizando, ao invés disso, os efeitos das mensagens argumentativas desenvolvidas deliberadamente para mudar atitudes. A discussão sobre o formato da comunicação da marca tem implicações na forma como ela é processada (DEIGHTON; ROMER; McQUEEN, 1989), e alguns autores defendem que concebendo um comercial de TV no formato de narrativa é possível transmitir um significado experiencial, na medida em que o consumidor se identifica com aquela estória e com as consequências do consumo da marca anunciada (BOLLER; OLSON, 1991).

Segundo o paradigma narrativo defendido pelo pesquisador da área de comunicação Walter Fisher (1987, veja também GRIFFIN, 2012), a retórica não é uma questão de argumentação, mas a oferta de boas razões por meio de uma história convincente, e, ainda, que não existe uma comunicação de ideias puramente descritiva ou didática. Fisher (1987) critica o paradigma do mundo racional, no qual algumas das premissas consideram o fato de (1) as pessoas serem essencialmente racionais; (2) de as pessoas tomarem decisões com base em argumentos; e (3) que a racionalidade é determinada pelo quanto sabemos e quão bem argumentamos. Ao contrário, Fisher (1987) defende o paradigma narrativo, em que, para citar algumas premissas, (1) as pessoas são essencialmente contadoras de estórias; (2) a racionalidade narrativa é determinada pela coerência e fidelidade de nossas estórias; e (3) o mundo é um conjunto de estórias das quais escolhemos algumas, e dessa forma constantemente recriamos nossas vidas.
Na psicologia, Bruner (1986) também divide em duas as formas de representação da realidade e forma de pensar. Ele critica o pensamento lógico-dedutivo chamado por ele de paradigmático - que enfoca a realidade física e os fatos observáveis, e no qual a forma de pensar é matemática e envolve a lógica (BRUNER, 1986). Ele defende o pensamento narrativo, que diz respeito à realidade psíquica, operando com questão da experiência humana, com crenças e dúvidas, com intenções, desejos e emoções.

Elaborado primeiramente por Green e Brock (2000) e confirmado em outros trabalhos que se seguiram (WANG; CALDER, 2006; ESCALAS, 2007; PHILLIPS; McQUARRIE, 2010), o processamento via narrativa tem mostrado afetar a persuasão por meio de um mecanismo chamado transportation, definido por alguns autores como a imersão dentro de um texto/estória (GREEN; BROCK, 2000), ou o processo de informação narrativa no qual uma pessoa não apenas assiste a uma informação como é absorvida no fluxo da estória, de um modo agradável e ativo (WANG; CALDER, 2006).

O mecanismo de transportation, que explica melhor o efeito da narrativa no consumidor, foi usado no livro de Gerrig (1993) e descreve o receptor como alguém que é transportado a um outro mundo e "retorna" modificado por essa "jornada". Seguem abaixo os elementos que ocorrem na experiência literal de transportation (GERRIG, 1993, p. 10-11):

I) Alguém - o viajante - é transportado;

II) por algum meio de transporte (livros, filmes e outros tipos de estórias);

III) como resultado de ter que desempenhar certas ações (na medida em que seu pensamento e emoção se envolvem no mundo narrativo);

IV) o viajante vai a certa distância de seu mundo de origem (não apenas em termo de espaço e em tempo, mas no que diz respeito aos ajustes necessários para compreender e aceitar o novo mundo);

V) o que torna alguns aspectos do mundo de origem inacessíveis (algumas das previsões e raciocínios do contexto de origem não funcionam mais);

VI) e o viajante retorna ao mundo de origem, modificado, de alguma forma, 
pela jornada (algumas estruturas mentais se modificam com esse tipo de experiência).

O mecanismo de transportation é distinto da elaboração cognitiva e pode formar e alterar as crenças e atitudes, o que pode resultar em crenças mais fortes e resistentes que a mudança baseada na retórica argumentativa (GREEN; BROCK, 2000). Green e Brock (2000) encontraram evidências de que o mecanismo de transportation influencia os leitores de três modos: fomentando vínculos com os personagens, diminuindo a contra-argumentação e resultando em interpretações dos eventos que simulam a vida real.

No contexto da propaganda, ao estimular o espectador a imaginar que "pode acontecer com ele", a narrativa acaba atraindo o consumidor para o enredo do anúncio o transportando-o para um mundo fictício moldado pela narrativa do anúncio original (McFERRAN; DAHL; GORN; HONEA, 2010). O transportation pode ser considerado um tipo de imagem mental (MACINNIS; PRICE, 1987; WYER; HUNG; JIANG, 2008) que os consumidores podem usar quando interagem com a comunicação de marketing e as narrativas. Nesse sentido, McFerran et al. (2010) o descrevem como um processo convergente envolvendo imagens mentais, cognição e emoção, todos eles focados nos eventos da narrativa, o que leva a um alto senso de realismo.

Em seu artigo sobre persuasão e autorreferência, Escalas (2007) procura testar o modelo de transportation em anúncios em versão que estimula a narrativa de transportation e outra que explora uma descrição analítica do produto. Este estudo consegue demonstrar que, quando espectadores são transportados para um anúncio narrativo que promove a autorreferência do consumidor ("imagine que você está correndo no parque...”) consegue persuadir tanto com argumentos fracos e fortes (ESCALAS, 2007). Ou seja, o efeito de transportation leva a avaliações melhores do produto independentemente da força dos argumentos, enquanto a versão que estimula a elaboração analítica, sem a presença de narrativa na referência do espectador ("gostaríamos de apresentar a você"), apresentou avaliações positivas apenas quando os argumentos eram fortes (ESCALAS, 2007).
Portanto, o trabalho de Green e Brock (2000) mostrou que a narrativa que "transporta" o consumidor leva à persuasão por meio da redução de respostas cognitivas negativas, pelo realismo da experiência e por meio de fortes respostas afetivas. Quando compara anúncios com autorreferência em formato narrativo em comparação a anúncios com autorreferência com formato mais analítico, a pesquisa de Escalas (2007) demonstra que o maior envolvimento do consumidor em processos narrativos permite uma redução da atenção aos possíveis argumentos fracos e aumenta a resposta afetiva, majorando a persuasão. Em resumo, o mecanismo de transportation é distinto da elaboração cognitiva e pode formar/alterar as crenças e atitudes, o que pode resultar em crenças mais fortes e resistentes que a mudança baseada na retórica argumentativa (GREEN; BROCK, 2000).

Da mesma forma que algumas variáveis como o nível de envolvimento, disposição para elaborar o anúncio e habilidade para fazer isso moderem os resultados e a rota de persuasão no ELM, a literatura mostra a provável importância da empatia com a estória ou personagem como possível moderadora do mecanismo de transportation, que por sua vez influencia o processo de persuasão. A empatia se refere à capacidade de uma pessoa imaginar-se no lugar do outro, de experienciar e entender o estado psicológico ou afetivo do outro (ARGO; ZHU; DAHL, 2008). Escalas e Stern (2003, p. 567) conceituam empatia como "uma resposta emocional derivada do estado ou condição emocional do outro e que é congruente com esse estado ou situação emocional". Deighton et al. (1989) mencionam que uma propaganda em formato de drama aumenta a audiência se o espectador se envolve na estória e passa a experienciar as preocupações e sentimentos dos personagens. A conexão entre os membros da audiência e os personagens facilitam a entrada na estória (ESCALAS, 2004; 2007).

\section{Contrastes entre os dois modelos}

Segundo Green e Brock (2000), no ELM e na abordagem narrativa, o elemento crítico é o montante de raciocínio que o indivíduo devota para a mensagem, tornando-o um processo 
considerado divergente, já que culmina em duas rotas de persuasão. O mecanismo de transportation, por sua vez, implica uma imersão no texto/estória, em um processo convergente com um único foco e distante temporariamente de esquemas e reflexões (GREEN; BROCK, 2000). Esses autores argumentam, portanto, que o transportation resultante da narrativa não se trata nem resulta em um processamento central ou periférico, sistemático ou heurístico, mas de outro processo de persuasão totalmente diferente. Segundo Green, Garst e Brock (2004) e Phillips e McQuarrie (2010), esse modelo recorre à corrente de pesquisas realizadas por Gilbert (1991), em que o conceito básico é que para compreender uma afirmação é necessário aceitá-la como verdade, ao menos provisoriamente. É requerido um esforço cognitivo para desacreditar no que está sendo lido, então a opção padrão é aceitar e acreditar.

No entanto, Phillips e McQuarrie (2010) ressaltam que os próprios autores do modelo de transportation - Green e Brock (2000) - negam que trabalhos retóricos como a propaganda possam gerar o efeito de transportation, pois a intenção persuasiva é óbvia e espera-se resistência por parte do consumidor. Os autores tratam de estórias e não de anúncios, o que poderia deixar em dúvida a utilidade da transportation para a persuasão de consumidores (PHILLIPS; McQUARRIE, 2010). Alguns autores (ESCALAS, 2007; NIELSEN; ESCALAS, 2010) manipularam o ceticismo em relação à propaganda, solicitando aos participantes analisar criticamente o anúncio em questão - em formato de narrativa - e conseguiram evidências de que consumidores céticos em relação à propaganda tendem a avaliá-la de forma analítica, inibindo ou cancelando o mecanismo de transportation.

Os dois modelos apresentados implicam diferentes tipos de "engajamento" por parte do consumidor. Enquanto o Elaboration Likelibood Model sugere uma exposição de natureza mais argumentativa, com a comunicação mais enfocada em argumentos fortes (rota central) ou em pistas que atraiam e influenciem os espectadores (rota periférica), o processo narrativo se vale da absorção dos consumidores pela estória contada na propaganda, em que atitudes podem ser formadas ou alteradas independentemente do grau de envolvimento prévio do consumidor. Dessa forma, os modelos oferecem caminhos diferentes para a mudança de atitudes.

\section{Considerações finais e sugestões de estudos futuros}

A persuasão envolve um esforço ativo para mudar atitudes, e esta é tarefa primordial para a comunicação, com impacto na estratégia de mensagem (o que dizer) e na execução (como dizer).

Autores que revisam em seus textos diversas teorias de persuasão e mudança de atitude afirmam que nem todas as atitudes são criadas da mesma maneira (PETTY; CACIOPPO, 1981; SOLOMON, 2011). Este artigo procurou contrastar dois modelos que rivalizam na literatura, mas que em conjunto possibilitam o alargamento do conhecimento acerca da formação e mudança de atitudes, com implicações relevantes para pesquisadores e profissionais nas áreas de psicologia, marketing e comunicação, além da contribuição para os campos da educação, do direito, entre tantas outras.

Os dois modelos envolvem, em princípio, ênfases em dois tipos de execução de comunicação diferentes - a propaganda de natureza mais argumentativa e a de natureza narrativa - que resultam em processamentos diferentes por parte dos consumidores.

Assim como o Elaboration Likelihood Model serve aos interesses de comunicadores há mais de 30 anos, o mecanismo de transportation, referenciado, é relevante para profissionais de marketing por causa de seu poder persuasivo (ESCALAS, 2007). Escalas (2004a) demonstrou que as propagandas conseguem facilitar o processo de transportation e maximizar a persuasão, conectando a propaganda ao autoconceito do consumidor, conseguindo "destacar-se diante do congestionamento de mensagens de marketing" (PIETERS; WARLOP; WEDEL, 2002) e criar conexões pessoais com os produtos (ESCALAS, 2004).

A literatura parece ver a evolução em complexidade do ELM (como sugere GRIFFIN, 2012) e a consolidação gradual do modelo narrativo como processo de persuasão. Existe, no entanto, bastante espaço para acomodar novos conhecimentos e explorar a relação entre os dois modelos de persuasão. Por exemplo, na pesquisa 
sobre o modelo de probabilidade de elaboração, na tentativa de obter uma visão, sob esse prisma, do processamento de estórias: as estórias contadas na propaganda, se fantasiosas, partiriam de uma rota periférica para atrair o consumidor? Ou é impossível a interpretação de estórias pelo paradigma clássico do ELM, sem considerar o mecanismo distinto de transportation para compreender o fenômeno que resulta na mudança de atitudes?

Em relação ao processo narrativo, ainda existe alguma discussão sobre seus efeitos e relevância no universo da comunicação, já que boa parte dos estudos sobre o processo narrativo vem da psicologia, usando textos da literatura, contos, sem a intenção de convencer, que é característica da propaganda e para a qual o consumidor aprende a interpretar de forma diferenciada (FRIESTAD; WRIGHT, 1994). E ainda são necessários estudos que avaliem variáveis moderadoras que podem causar algum impacto no processo de persuasão, como o ceticismo em relação à propaganda (ESCALAS, 2007) e a empatia em relação à estória ou personagem da propaganda (ARGO et al., 2008).

Ainda menciona-se o potencial de estudos na área de persuasão no contexto brasileiro e na comparação de nosso contexto com outros, já que a pesquisa apresentada na introdução deste trabalho reflete a atratividade que a propaganda representa para o consumidor brasileiro - fato este que pode representar diferenças e, por exemplo, um ceticismo menor se comparado a outros países e consumidores.

\section{Referências}

ADAVAL, R.; WYER, R. The role of narratives in consumer information processing. Journal of Consumer Psychology, v. 7, n. 3, p. 207-245, 1998.

AHUVIA, A. C. Beyond the extended self: loved objects and consumers' identity narratives. Journal of Consumer Research, v. 32, p. 171-184, 2005.

ARGO, J. J.; ZHU, R.; DAHL, D. W. Fact or fiction: na investigation of empathy differences in response to emotional melodramatic entertainment. Journal of Consumer Research, v. 34, n. 5, p. 614-623, 2008.
ARMSTRONG, J. S. Persuasive advertising: evidence-based principles. London: Palgrave Mcillan, 2010.

BELCH, G.E.; BELCH, M. A. Propaganda e promoção: uma perspectiva da comunicação integrada de marketing. São Paulo: McGraw-Hill, 2008.

BELK, R. W. Possessions and the extended self. Journal of Consumer Research, v. 15,n. 2, 139-168, 1988.

BOLLER, G. W.; OLSON,J. Experiencing ad meaning: crucial aspects of narrative/drama processing. In:HOLMAN, H.; SOLOMON, M. R. (Eds.). Advances in Consumer Research. Provo, UT: Association for Consumer Research, 1991. v. 18. p. 164-171.

BRUNER, J.Actual minds, possible worlds. Cambridge, MA: Harvard University Press, 1986.

BRUNER, J. Life as a narrative. Social Research, v. 71, n. 3, p. 691-710, 2004.

BUCHHOLZ, L. M.; SMITH, R. E. The role f consumer involvement in determining cognitive response to broadcast advertising. Journal of Advertising, v. 20, n. 1, p. 4-17, 1991.

CACIOPPO,J.T;;PETTY,R.E. The elaboration Likelihood model: the role of affect and affect-laden information processing in persuasion. In: CAFFERATA, P.; TYBOUT, A. (Eds.). Cognitive and affective responses to advertising. Lexington, MA: Lexington Books, 1989. p. 69-89

DEIGHTON,J.;ROMER, D.; McQUEEN,J.Using drama to persuade. Journal of Consumer Research, v. 16, n. 3, p. 335-343, 1989.

ESCALAS, J. E. Imagine yourself in the product. Journal of Advertising, v. 33, n. 2, p. 37-48, 2004.

ESCALAS,J.E. Narrative versus Analytical Self-Referencing and Persuasion. Journal of Consumer Research, v. 34, n. 4, p. 421-429, 2007.

ESCALAS, J. E.; BETTMAN, J. R. Using narratives and autobiographical memories to discern motives. In: RATNESHWAR, S.; MICK, D. G.; HUFFMAN, C. (Ed.). The why of consumption: perspectives on consumer motives, goals, and desires. New York: Routledge, 2000. p. 237-258. 
ESCALAS, J. E.; STERN, B. B. Sympathy and empathy: emotional responses to advertisin dramas, Journal of Consumer Research, v. 29, p. 566-578, 2003.

FISHER, W. Human communication as narration: toward a philosophy of reason, value and action. University of South Carolina Press, Columbia, SC, 1987.

FISHER, W. Narrative paradigm. In: GRIFFIN, E. Afirst look at communication theory. New York: MMcGrawHill, 2012. p. 308-318.

FOURNIER, S. Consumers and their brands: developing relationship theory in consumer research. Journal of Consumer Research, v. 24, n. 4, p. 343-373, 1998.

FRIESTAD, M.; WRIGHT, P. The persuasion knowledge model: how people cope with persuasion attempts. Journal of Consumer Research, v. 12, p. 1-31, 1994.

GERRIG, R.J. Experiencing narrative worlds. Yale University Press, New Haven, CT:, 1993.

GILBERT, D. T. How mental systems believe. American Psychologist, v. 46, n. 2, p. 107-119, 1991.

GREEN, M. Storytelling in teaching. American Psychology Society Observer, v. 77, n. 4, p. 1-8, 2004.

GREEN, M. C.; BROCK, T. C. The role of transportation in the persuasiveness of public narratives. Journal of Personality and Social Psychology, v. 79, n. 5, p. 701-721, 2000.

GREEN, M. C.; GARST, J.; BROCK, T. C. The power of fiction: determinants and boundaries. In: SHRUM, L. J. (Ed.). The psychology of entertainment media: blurring the lines between entertainment and persuasion. New Jersey: Lawrence Erlbaum Associates, 2004. p. 161-176.

GRIFFIN, E. A first look at communication theory. New York: McGraw-Hill, 2012.

HAUGTVEDT, C. P.; KASMER, J .A. Attitude change and persuasion. In: HAUGTVEDT, C. P.; HERR, P. M.; KARDES, F. R. Handbook in consumer psychology. New York: Taylor \& Francis Group, 2008. p. 419-436.

IBOBE. População brasileira faz avaliação positiva da publicidade e reconhece seu papel na sociedade. Disponível em: <http://www.ibope.com.br/calandraWeb $/$ servlet $/$ CalandraRedirect?temp $=5 \&$ proj $=$ PortalI BOPE\&pub $=\mathrm{T} \& \mathrm{db}=$ caldb\&comp $=$ Notícias\&docid $=$ D4F4D2621A5AE87783257700006CAB71 >. Acesso em: fev. 2012.
LEONG, S. M.; ANG, S. H.; HENG, L. Using drama to persuade: the effects of involvement and ad form on persuasion. Asia Pacific Advances in Consumer Research, v. 1, p. 261-264, 1994.

MACINNIS, D. J.; PRICE, L. L. The role of imagery in information processing: review and extensions. Journal of Consumer Research, v. 13, p. 473-491, 1987.

MAGALHÃES, M. L. Pensamento narrativo e linguagem narrativa. In: CORREIA, A. M.; COQUET, E. (Coords). Diálogos com a arte. Braga: Centro de estudos da criança da Universidade do Minho, 2009. p. 1-12.

McCRACKEN, G. Culture and consumption: a theoretical account of the structure and movement of the cultural meaning of consumer goods. Journal of Consumer Research, v. 13, n. 1, p. 71-84, 1986.

McFERRAN, B.; DAHL, D. W.; GORN, G. J.; HONEA, H. Motivational determinants of transportation into marketing narratives. Journal of Consumer Psychology, v. 20, n. 3, p. 306-316, 2010.

NIELSEN, J. H.; ESCALAS, J. E. Easier is not always better: the moderating role of processing type on preference fluency. Journal of Consumer Psychology, v. 20, p. 295-305, 2010.

PERACCHIO, L. A.; ESCALAS, J. E. Tell me a story: crafting and publishing research in consumer psychology. Journal of Consumer Psychology, v. 18, p. 197-204, 2008.

PERLOFF, R. M. The dynamics of persuasion: communication and attitudes in the 21 st Century. New York: Routledge, 2010.

PETROVA, P. K.; CIALDINI, R. B. Evoking the imagination as strategy of influence. In: HAUGTVEDT, C. P.; HERR, P. M.; KARDES, F. R. Handbook in consumer psychology. New York: Taylor \& Francis Group, 2008. p. 505-523.

PETTY, R. E.; CACIOPPO, J. T. Attitudes and persuasion: classic and contemporary approaches. Dubuque: Wm.C.Brown Company Publishers, 1981.

PETTY, R. E.; CACIOPPO, J. T.; SCHUMANN, D. Central and peripheral routes to advertising effectiveness: the moderating role of involvement. Journal of Consumer Research, v. 10, n. 2, p. 135-146, 1983. 
PHILLIPS, B. J.; McQUARRIE, E. F. Narrative and persuasion in fashion advertising. Journal of Consumer Research, v. 37, p. 368-392, 2010.

PIETERS, R., WARLOP, L., \& WEDEL, M.. Breaking through the clutter: Benefits of advertisement originality and familiarity for brand attention and memory. Management Science, v. 48,n. 6, p. 765-781, 2002.

PHILLIPS, G. Let's fix advertising. Advertising Age, 20 maio 2002. Disponível em: <http://adage.com/ article/viewpoint/fix-advertising/52130/>. Acesso em: fev. 2012.

POLKINGHORNE, D. E. Narrative and self-concept. Journal of Narrative and life history, v. 1, n. 2/3, p. 135-153, 1991.

SCHANK, R. C.; ABELSON, R. P. Knowledge and memory: the real story. In: WUER, R.S. (Ed.). Advances in social cognition. Hillsdale, NJ: Erldaum, 1995. v. 8. p. $1-85$.

SHIMP, T. A. Comunicação integrada de marketing: propaganda e promoção. Porto Alegre: Bookman, 2009.

SOLOMON, M. R. O comportamento do consumidor: comprando, possuindo e sendo. Porto Alegre: Bookman, 2011.

VAKRATSAS, D.; AMBLER, T. How advertising Works. What do we really know? Journal of Marketing, v. 63. p. 26-43, 1999.
WANG, J.; CALDER, B. J. Media transportation and advertising. Journal of Consumer Research, v. 33, n. 2, p. 151-162, 2006.

WOODSIDE, A. G.; SOOD, S.; MILLER, K. E. When consumers and brands talk: storytelling theory and research in psychology and marketing. Psychology \& Marketing, v. 25, n. 2, p. 97-145, 2008.

WYER, R. S.; HUNG, I. W.; JIANG, Y. Visual and verbal processing strategies in consumer comprehension and judgment. Journal of Consumer Psychology, v. 18, n. 4, p. 244-257, 2008.

ZAICHKOWSKY, J. L. Measuring the involvement construct. Journal of Consumer Research, v. 12, p. 341-352, 1985.

ZHENG, L. The impact of narrative focus, vividness of product depiction, mental imagery ability, and need for cognition on transportation in narrative advertising. 2010. (unpublished doctoral dissertation) - The University of Alabama, 2010.

Recebido: 30/06/2012

Received: 06/30/2012

Aprovado: 16/07/2012

Approved: 07/16/2012 